\title{
Sinodalidad y laicado. Corresponsabilidad y participación de los laicos en la vocación sinodal de la Iglesia
}

\section{Synodality and Laity. Co-Responsibility and Participation of Lay People in the Synodal Vocation of the Church}

\section{Carmen PEÑA}

Profesora Propia Agregada

Universidad Pontificia Comillas. Facultad de Derecho Canónico. Madrid

orcid 0000-0002-5817-8288

cpgarcia@comillas.edu

Resumen: En el pontificado de Francisco, la sinodalidad aparece como un criterio clave en la concepción misma de la Iglesia y en el ejercicio del gobierno eclesial. Este estudio contiene una reflexión sobre la vocación sinodal del Pueblo de Dios y del laicado en concreto, mediante la profundización en las consecuencias del reconocimiento eclesial de los derechos fundamentales de los fieles y de su participación en el triple munus de Cristo. La actual regulación canónica abre amplios campos de actuación para los laicos, superando por la vía de la legislación y de la praxis, las discusiones doctrinales relativas a la vinculación entre el orden sagrado y el ejercicio de la potestad de gobierno. Asimismo, se analiza la regulación de los ministerios laicales en el canon 230, valorando su coherencia con los presupuestos eclesiológicos subyacentes.

Palabras clave: Ministerios, Mujer, Juez laico, Fieles, Oficios eclesiásticos, Sacerdocio común, Teólogos.
Abstract: Under Pope Francis, synodality is a key concept for understanding the Church and the exercise of ecclesiastical government. This paper reflects on the synodal vocation of the People of God, and of the laity in particular, by exploring in depth the consequences of the ecclesial recognition of the fundamental rights of the laity and their participation in the threefold munus of Christ. The current canonical regulation envisages broad areas of action for the laity. Such law and ecclesiastical praxis help move beyond doctrinal debates regarding the link between holy orders and the exercise of the power of government. In addition, the author analyzes the regulation of lay ministries in canon 230, appraising their coherence with underlying ecclesiological principles.

Keywords: Ministries, Women, Lay Judge, Faithful, Ecclesiastical Offices, Common Priesthood, Theologians. 
SumArio: 1. Planteamiento y enfoque del tema. 2. Estatuto jurídico de los fieles laicos dentro del Pueblo de Dios: algunos derechos especialmente relevantes desde la perspectiva de la sinodalidad. 3. Consecuencias del derecho de manifestación de la propia opinión (c. 212) en el marco de la sinodalidad. 3.1. Reconocimiento del carácter fundamental y constitucional del derecho-deber de los laicos a expresar la propia opinión en cuestiones eclesiales. 3.2. Conveniencia de una revalorización de la función consultiva. 3.3. Un supuesto especial: el papel de los teólogos y canonistas. 4. Participación de los laicos en el ejercicio de la función de gobierno en la Iglesia. 5. Participación de los laicos en el ejercicio del munus santificandi: la problemática regulación de los ministerios laicales. 6. Conclusiones.

\section{Planteamiento y enfoque Del tema}

- 1 principio teológico de la sinodalidad es uno de los conceptos que, derivado de la renovación eclesiológica del Concilio Vaticano II, ha adquirido notable relevancia en el pontificado del papa Francisco, apareciendo como un criterio fundamental no solo para la reciente reforma de la normativa del Sínodo de los Obispos ${ }^{1}$, sino para todo el ejercicio del gobierno en la Iglesia ${ }^{2}$.

Ello ha motivado, en los últimos tiempos, un renovado interés -a nivel teológico, canónico y pastoral- por la profundización en este concepto de sinodalidad, siendo especialmente relevante el reciente docu-

1 Francisco, Constitución apostólica Episcopalis communio sobre el Sínodo de los Obispos, de 15 de septiembre de 2018: http://w2.vatican.va/content/francesco/es/apost_ constitutions/documents/papa-francesco_costituzione-ap_20180915_episcopaliscommunio.html (consultado el 6 de mayo de 2019).

2 La llamada a una reforma de la Iglesia en clave sinodal es un tema recurrente en el pontificado de Francisco: baste citar su conocido discurso de 17 de octubre de 2015 con ocasión del 50 aniversario de la institución del Sínodo de los Obispos, donde el Papa recordaba que «la sinodalidad, como dimensión constitutiva de la Iglesia, nos ofrece el marco interpretativo más adecuado para comprender el mismo ministerio jerárquico» e insistía en «el compromiso de edificar una Iglesia sinodal, misión a la cual todos estamos llamados, cada uno en el papel que el Señor le confía», pues «el camino de la sinodalidad es el camino que Dios espera de la Iglesia del tercer milenio»: http://w2.vatican.va/content/francesco/es/speeches/2015/october/documents/papafrancesco_20151017_50-anniversario-sinodo.html (consultado el 6 de mayo de 2019). 
mento de la Comisión Teológica Internacional La sinodalidad en la vida y misión de la Iglesia ${ }^{3}$, que constituye una valiosa aportación que precisa y profundiza en un concepto (sinodalidad) y un adjetivo (sinodal) de importancia creciente, que, si bien no aparecen explícitamente citados en los documentos conciliares, tienen su origen y «se encuentran en el corazón de la obra de renovación promovida por él» ${ }^{4}$. Asimismo, se han producido interesantes seminarios de estudio sobre este concepto y sus consecuencias en la vida eclesial, en el que teólogos y canonistas han reflexionado sobre las diversas dimensiones implicadas en la definición de la sinodalidad y en el ejercicio de la misma ${ }^{5}$.

Tanto el documento de la CTI, como los citados seminarios, prestan atención, entre otros, a la cuestión de los sujetos de la sinodalidad, pues esta no afecta únicamente al Romano Pontífice o al colegio episcopal, sino que alcanza a todo el Pueblo de Dios en su conjunto, incluido naturalmente el laicado.

La cuestión del papel y misión de los laicos en la vida y misión de la Iglesia, desde esta perspectiva sinodal, plantea sugerentes interrogan-

3 COMISIÓN TEOLÓGICA INTERNACIONAL (= CTI), La sinodalidad en la vida y misión de la Iglesia, 2018: http://www.vatican.va/roman_curia/congregations/cfaith/cti_documents/rc_cti_20180302_sinodalita_sp.html (consultado el 16 de abril de 2019).

4 CTI, La sinodalidad en la vida y misión de la Iglesia, n. 6.

5 Especial relevancia tuvo, en este sentido, el seminario internacional de estudio organizado por la Secretaría del Sínodo de los Obispos, que se celebró en Roma del 6 al 9 de febrero de 2016, en el contexto de la reforma de la normativa del Sínodo auspiciada por Francisco, tras su discurso con ocasión del cincuenta aniversario de la institución de sínodo de los obispos por Pablo VI (17-X-2015). El volumen de las actas fue publicado en L. BALdisseri (ed.), A cinquant'anni dall'Apostolica Sollicitudo. Il Sinodo dei Vescovi al servizio di una Chiesa sinodale. Atti del Seminario di studio organizzato dalla Segreteria generale del Sinodo dei Vescovi (Città del Vaticano, 6-9 febbraio 2016), Libreria Editrice Vaticana, Città del Vaticano 2016; puede verse un sugerente comentario al mismo en A. VIANA, Sinodalidad y Derecho canónico. Un seminario organizado por la Secretaría general del Sínodo de los Obispos, Estudios Eclesiásticos 92 (2017) 683-701. Recientemente, la Fundación Pablo VI ha celebrado en Madrid, los días 28 a 30 de abril de 2019, un Seminario internacional de estudio con el título Hacia una Iglesia sinodal: del papa Pablo VI a Francis$c o$, en el que han participado teólogos y canonistas españoles, italianos e iberoamericanos, abordando cuestiones sobre sinodalidad y reforma, la sinodalidad ante los retos del ecumenismo, la reforma de la Iglesia en clave sinodal desde la experiencia latinoamericana, o los sujetos de la sinodalidad. Cfr. https://www.fpablovi.org/index.php/pablo-viseminario-internacional (consultada el 12 de mayo de 2019); puede verse una crónica del encuentro en Vida Nueva, n. 3.128, 4-10 de mayo de 2019, 8-15. 
tes y retos, no solo a la teología, sino también al derecho canónico, en cuanto que este concreta, desarrolla y da eficacia normativa, vinculante para todos los miembros de la Iglesia, a las concepciones eclesiológicas de cada momento histórico ${ }^{6}$. Como recoge el documento de la Comisión Teológica Internacional, la concreción y realización de esa sinodalidad exigirá tomar en consideración -y en su caso revisar- lo dispuesto en el actual ordenamiento canónico ${ }^{7}$, lo que implicará un discernimiento tanto de la potencialidad del concepto de sinodalidad como de los cauces concretos en que puede hacerse efectivo. Asimismo, en este discernimiento, puede ser interesante pararse a tomar en consideración algunos datos que están ya presentes en el derecho actualmente vigente y que pueden contribuir a la reflexión sobre este tema y a dar nuevo impulso a la dinámica sinodal.

En esta aproximación a la sinodalidad desde la perspectiva de sus sujetos, y, más concretamente, del laicado, resulta comúnmente aceptado, como reitera repetidamente el documento de la CTI, que «el concepto de sinodalidad hace referencia a la corresponsabilidad y participación de todo el Pueblo de Dios en la vida y misión de la Iglesia» (n. 7), partiendo de «la dignidad bautismal y la corresponsabilidad de

6 A este carácter instrumental hacía referencia la constitución apostólica por la que se promulgó el Código de 1983, al afirmar que la función del Derecho Canónico «no es en modo alguno sustituir en la vida de la Iglesia y de los fieles la fe, la gracia, los carismas y sobre todo la caridad», sino permitir su crecimiento ordenado. En este sentido, se insistía en que «este nuevo Código puede considerarse como un gran esfuerzo por traducir a lenguaje canónico la eclesiología conciliar. Y aunque es imposible verter perfectamente en lenguaje canónico la imagen de la Iglesia descrita por la doctrina del Concilio, el Código ha de ser referido siempre a esa misma imagen como al modelo principal cuyas líneas debe expresar él en sí mismo, en lo posible, según su propia naturaleza»: JuAN PABLO II, Constitución Apostólica Sacrae disciplinae leges, de 25 de enero de 1983, por la que se promulga el Código de Derecho Canónico: AAS 75 (1983) II, 3.

7 En su capítulo III, dedicado a La realización de la sinodalidad: sujetos, estructuras, procesos, acontecimientos sinodales, destaca el documento la relevancia de esta aproximación canónica: «La inteligencia teológica de la sinodalidad en la perspectiva eclesiológica del Concilio Vaticano II invita a reflexionar sobre las modalidades concretas de su realización. Se trata de examinar, en líneas generales, lo que actualmente está previsto por el ordenamiento canónico para poner en evidencia el significado y las potencialidades y darles nuevo impulso, discerniendo al mismo tiempo las perspectivas teológicas para su pertinente desarrollo»: CTI, La sinodalidad en la vida y misión de la Iglesia, cit., n. 71. 
todos los fieles» (n. 72) y destacando la importancia de la participación de los fieles laicos en esta misión eclesial, así como algunos obstáculos que, en ocasiones, se pone a dicha participación (n. 73), como ya señalaba críticamente Evangelii Gaudium ${ }^{8}$. En la misma línea, recordaba recientemente Francisco que «el camino sinodal comienza escuchando al pueblo, que "participa también de la función profética de Cristo", según un principio muy estimado en la Iglesia del primer milenio: Quod omnes tangit ab omnibus tractari debet $\gg$.

Tras el Concilio Vaticano II, es un dato comúnmente aceptado, teológica y canónicamente, que todos los fieles -no solo los ordenadosparticipan y son titulares y corresponsables de la misión evangelizadora de la Iglesia, participando, cada uno según su propia condición, del triple munus -santificandi, docendi y regendi- que Cristo, como Sacerdote, Profeta y Rey, ha confiado a su Iglesia. Esta renovación eclesiológica conciliar ha dado lugar a un progresivo desplazamiento conceptual -no solo terminológico- del discurso sobre esta cuestión, pasándose de la clásica potestad de jurisdicción (potestas iurisdictionis) a la potestad de gobierno o de régimen (potestas regiminis) y, con mayor propiedad, al munus regendi o función de gobierno, e, incluso, al concepto de ministerialidad, que refleja mejor la dimensión de servicio que tiene toda potestad o función en la Iglesia ${ }^{10}$.

En un sentido propio, por tanto, hablar de ministerialidad laical es hablar de la corresponsabilidad de los laicos en la misión de la Iglesia, desde la conciencia del sacerdocio común de todos los fieles, ministe-

8 «Los laicos son simplemente la inmensa mayoría del Pueblo de Dios. A su servicio está la minoría de los ministros ordenados. Ha crecido la conciencia de la identidad y la misión del laico en la Iglesia. (...) Pero la toma de conciencia de esta responsabilidad laical que nace del Bautismo y de la Confirmación no se manifiesta de la misma manera en todas partes. En algunos casos porque no se formaron para asumir responsabilidades importantes, en otros por no encontrar espacio en sus Iglesias particulares para poder expresarse y actuar, a raíz de un excesivo clericalismo que los mantiene al margen de las decisiones»: FRANCISCO, Exhortación Apostólica Evangelii Gaudium, de 24 de noviembre de 2013, n. 102.

9 Francisco, Discurso de 17 de octubre de 2015 con ocasión del 50 aniversario de la institución del Sinodo de los Obispos, cit.

10 F. S. REA, L'esercizio della potestà giudiziaria del fedele laico attraverso il prisma della Potestas gubernandi in Ecclesia. Sollecitazioni teologiche e canonistiche per una "Chiesa in uscita”, Stato, Chiese e pluralismo confessionale (www.statoechiese.it) 37 (2018) 18. 
rialidad derivada del bautismo. La ministerialidad laical, por tanto, es más profunda y amplia que los ministerios laicales, término que hace referencia a los concretos ministerios del lectorado y el acolitado, recibidos mediante el rito litúrgico prescripto, los cuales vienen regulados -de forma no exenta de polémica- en el c. 230 del Código de Derecho Canónico, recogiendo lo establecido por Pablo VI en su M.P. Ministeria Quaedam, de 15 de agosto de 1972.

En este estudio, se pretende contribuir a la reflexión sobre la vocación sinodal del Pueblo de Dios y del laicado en concreto, para lo cual se profundizará en las consecuencias deducibles del reconocimiento eclesial -también a nivel legislativo- de los derechos fundamentales de los fieles, incluidos los laicos, y de su participación en el triple munus de Cristo, así como en los amplios campos de actuación que, para los fieles laicos, abre la actual regulación canónica, superando por la vía de la legislación y de la praxis las discusiones doctrinales relativas a la vinculación entre el orden sagrado y el ejercicio de la potestad de gobierno ${ }^{11}$. Asimismo, se prestará atención a la regulación que de los ministerios laicales propiamente dichos hace el derecho vigente en el canon 230, valorando su coherencia con los presupuestos eclesiológicos subyacentes.

\section{Estatuto jurídico de los FIELES LAICOS DENTRO \\ DEl Pueblo de Dios: algunos DERECHOS ESPECIALMENTE RELEVANTES DESDE LA PERSPECTIVA DE LA SINODALIDAD}

Entre las novedades conciliares que tuvieron su posterior "traducción" canónica e incorporación al Derecho de la Iglesia en el Código de 1983, se halla la renovada concepción eclesiológica de la Iglesia como Pueblo de Dios y de la participación de todos los fieles en la misión evangelizadora de la Iglesia y en el triple munus de Cristo, dando lugar a un reconocimiento expreso de la radical igualdad de los bautizados y de la existencia de unos derechos fundamentales de los fieles ${ }^{12}$. Estos

11 En este trabajo se utilizará el término laicos en el sentido de no ordenados, partiendo de la distinción bimembre -constitucional- del c. 207 entre clérigos o ministros ordenados (Obispos, sacerdotes y diáconos) y laicos.

12 Entre las novedades relevantes del Código destaca expresamente la c.a. Sacrae disciplinae leges las siguientes, directamente derivadas de la eclesiología conciliar: «De entre los elementos que expresan la verdadera y propia imagen de la Iglesia, han de men- 
derechos fundamentales, configurados como derechos propios e inalienables derivados del Bautismo, tienen verdaderamente rango constitucional y, aunque vienen explicitados en el Libro II (Del Pueblo de Dios) del Código de Derecho Canónico, en los cc. 204-223, son previos a toda regulación positiva, de modo que no provienen de una "concesión” graciosa de la autoridad eclesiástica, sino que derivan directamente del Bautismo, en cuanto sacramento que llama a todos los fieles laicos a participar vivamente en la comunión y misión de la Iglesia ${ }^{13}$.

Esta participación de todos los fieles, según su propia condición, en la triple misión de Cristo -a la que alude el c. 204- aparece como la base y el fundamento de la radical igualdad de todos los bautizados que declara el c. 208, superando así la comprensión marcadamente clericalista y jerarquizada que caracterizaba el Código de 1917. Como ha destacado la práctica totalidad de la doctrina, el mismo dato de tomar como punto de partida los derechos comunes a todos los fieles, con independencia de su condición, así como el hecho de que los derechos propios y específicos de los laicos se reconozcan inmediatamente después de los derechos de los fieles (cc. 224-231) ${ }^{14}$, apunta ya a un cambio en la comprensión eclesial, conforme a la cual el estatuto de los laicos deberá ser tratado, no desde una dialéctica de oposición, sino desde una dinámica de comunión, dentro de la cual las diversas vocaciones aparezcan como complementarias, no contrapuestas. En definitiva, el sujeto de la misión

cionarse principalmente la doctrina que propone a la Iglesia como Pueblo de Dios y a la autoridad como servicio... y la doctrina según la cual todos los miembros del Pueblo de Dios participan, a su modo propio, de la triple función de Cristo, la sacerdotal, la profética y la regia, a la cual doctrina junta también la que considera los derechos y deberes de los fieles cristianos y concretamente de los laicos».

13 Chistifideles Laici, 29; Apostolicam Actuositatem, 19.

14 Sobre la renovada regulación canónica del laicado, entre otros, AA. VV., La misión del laico en la Iglesia y en el mundo, Eunsa, Pamplona 1987; J. M. DíAz MOREnO, Los fieles cristianos y los laicos, en M. CoRTÉs - J. SAN José (coords.), Derecho Canónico, vol. I: El Derecho del Pueblo de Dios, BAC, Madrid 2006, 155-185; L. NaVArro, La condizione giuridica del laico nella canonistica dal Concilio Vaticano II ad oggi, Ius Ecclesiae 23 (2011) 319-338; M. E. Olmos ORTEGA, Los laicos en los órganos de gobierno de la Iglesia (con especial referencia a la mujer), en AA. VV., El laicado en la Iglesia, UPSA, Salamanca 1989, 97-122; C. PEÑA, La vocación laical: marco canónico, en E. EsTÉvEZ (coord.), Hombres y mujeres de Espíritu en el siglo XXI, UPSA (Cátedra Pedro Poveda 8), Salamanca 2012, 409-419. 
es la entera Iglesia, como Pueblo de Dios, con la totalidad de sus ministerios y vocaciones ${ }^{15}$.

Por supuesto, estos derechos no son ilimitados, actuando el bien común de la Iglesia y los derechos de los demás como límite de los mismos (c. 223), pero su reconocimiento explícito en el Código de Derecho Canónico supone un avance significativo, en cuanto que estos derechos, por ser fundamentales, obligan también a la autoridad eclesial, de modo que la posterior regulación del ejercicio de estos derechos deberá hacerse desde esta clave, evitando dejar sin contenido los mismos mediante regulaciones arbitrarias o reduccionistas.

Entre los derechos y deberes que corresponden a todos los fieles cristianos en virtud del Bautismo, con independencia de su condición clerical o laical, se encuentran derechos tan significativos como el derecho de iniciativa apostólica (c. 216) y el derecho-deber a trabajar en la evangelización (c. 211), muy vinculado con la dimensión misionera de la Iglesia. Este derecho-deber viene reiterado -ya específicamente referido a los laicos- en el c. 225, que lo reconoce tanto individual como asociadamente, si bien hace una especial referencia al deber de perfeccionar el orden temporal con el espíritu evangélico, mientras que el c. 227 reconoce el derecho de los laicos a la libertad de actuación en los asuntos terrenos, y el c. 226, en relación con la importante función eclesial de la familia, se refiere al derecho-deber de edificar el Pueblo de Dios a través del matrimonio y la familia, así como al derecho-deber de educar a los hijos.

Dentro de estos derechos genéricamente reconocidos a todos los fieles ${ }^{16}$, resulta de especial interés, de cara a la sinodalidad y al papel de los laicos, el derecho de asociación, el derecho de fundar y dirigir asociaciones (c. 215), que se reconoce en el Código actual con toda amplitud, frente a la rigidez y limitaciones de la regulación anterior, donde la iniciativa del asociacionismo quedaba reservada en exclusiva a la autoridad jerár-

15 J. ManZanares, La figura del laico en el Sínodo episcopal de 1987, en AA. Vv., El laicado en la Iglesia, cit., 79-80.

16 Otros derechos fundamentales de los fieles serían el derecho de reunión (c. 215); el derecho a la libre elección del estado de vida (c. 219); el derecho a la buena fama y a la propia intimidad (c. 220); el derecho a recibir ayuda espiritual de los Pastores (c. 213) y formación cristiana (c. 217); el derecho a no ser sancionados si no es según ley, y a reclamar y a defender en los tribunales eclesiásticos los propios derechos, también frente a la autoridad jerárquica, en caso de posible abuso de esta (c. 221); etc. 
quica. Este reconocimiento del derecho de asociación como un derecho fundamental de los fieles -y, muy significativamente, de los laicos- ha supuesto una profunda renovación del fenómeno asociativo y carismático, que ha proliferado en las últimas décadas, al haberse sustituido la rígida regulación anterior por una norma-marco de amplitud suficiente como para que puedan encontrar encaje la gran variedad de fenómenos asociativos que el Espíritu ha ido inspirando en la Iglesia, si bien la concreta articulación de nuevas realidades eclesiales no deja de plantear algunas oscuridades ${ }^{17}$. Se trata, en cualquier caso, de un derecho que presenta una clara vinculación con la dimensión sinodal de la Iglesia, en cuanto que estas nuevas realidades eclesiales, frecuentemente carismáticas, «pueden ofrecer experiencias significativas de articulación sinodal de la vida de comunión y dinámicas de discernimiento comunitario puestas en práctica en el interior de ellas» (CTI, n. 74).

Muy relacionado con esta dimensión sinodal está también el derecho fundamental a vivir la propia espiritualidad (c. 214). Este canon reconoce -dentro siempre del marco de su conformidad con la doctrina de la Iglesia- un sano pluralismo espiritual, que prohíbe imponer en la Iglesia un modo uniforme, "único y exclusivo" de vivir la fe cristiana o de servir a la misión, sin respetar sensibilidades espirituales, tradiciones religiosas, contextos culturales, etc. Este derecho a la propia espiritualidad exige no solo inmunidad de coacción a la hora de elegir la propia forma de vida espiritual, sino también, en términos positivos, el reconocimiento y la valoración de lo carismático, de las nuevas formas o movimientos eclesiales que vayan surgiendo, sin coartar la libertad con sospechas apriorísticas sobre la eclesialidad de las nuevas realidades, o con imposiciones uniformizantes a la hora de articular el apostolado.

En este sentido, conviene destacar que, aun cuando sea lícito hablar de vocación laical o de espiritualidad laical -en paralelismo con la vocación o espiritualidad clerical o religiosa- es claro que dentro de este

17 En la actual regulación canónica de las asociaciones de fieles (cc. 298-329) caben fenómenos muy diversos, tanto por sus fines, como por sus componentes (clérigos, laicos, clérigos y laicos juntos, consagrados), por su extensión, por su estructura, por su naturaleza (pública o privada), etc. Sobre la regulación canónica del derecho de asociación y las cuestiones abiertas hoy día, resulta de interés J. A. FuENTES (ed.), Las asociaciones de fieles. Aspectos canónicos y civiles, Eunsa, Pamplona 2011. 
tipo genérico de vida espiritual caben, a su vez, muchas formas concretas de espiritualidad que también merecen protección. En este sentido, no hay una única vocación y espiritualidad laical, sino que los modos de vivir esta radical y común vocación pueden ser muy diversos y todos ellos en principio legítimos. La vida espiritual no se puede encasillar en moldes rígidos, ni cabe atribuir, con carácter monopolístico, una determinada espiritualidad a los laicos con el pretexto de que así viven y realizan mejor su vocación laical ${ }^{18}$.

Pero, indudablemente, el derecho fundamental más relevante para el tema de la sinodalidad es el formulado en el c. 212, que reconoce el derecho a la manifestación de las propias necesidades y deseos a los Pastores (c. 212.2)- y, muy destacadamente, el derecho-deber a la manifestación de la propia opinión sobre el bien de la Iglesia, tanto a los Pastores como a los demás fieles, que viene recogido en el c. 212.3.

\section{CONSECUENCIAS DEL DERECHO DE MANIFESTACIÓN}

DE LA PROPIA OPINIÓN (C. 212) EN EL MARCO DE LA SINODALIDAD

Los derechos reconocidos en el c. 212.2 y, muy especialmente, en el c. 212.3 suponen el reconocimiento, por parte de la Iglesia, de la responsabilidad y autonomía de los fieles (laicos incluidos) en su relación con los Pastores: al reconocer el derecho e incluso el deber de los fieles -según su conocimiento, competencia y prestigio- de informar y manifestar su opinión sobre la marcha de la Iglesia, el legislador está poniendo de manifiesto, de modo normativo, la corresponsabilidad de los laicos y su participación en la triple misión de Cristo.

Por supuesto, este derecho de opinión deberá ejercerse de modo respetuoso y en una dinámica de comunión, pero resulta interesante destacar que puede hacerse abiertamente ("a los demás fieles", dice el canon), no necesariamente de modo reservado a la Jerarquía, lo que supone una muestra de sana libertad y también, de reconocimiento del papel de los fieles -no solo de los Pastores- en el juicio sobre las necesidades eclesiales.

Expresión excelente de este derecho fundamental a manifestar la propia opinión sobre la vida eclesial es la participación de los laicos en

18 D. Cenalmor, Sub c. 214, en Comentario exegético al Código de Derecho Canónico, II, Eunsa, Pamplona 1996, 107. 
los diversos consejos establecidos -a nivel parroquial, diocesano o universal- como modos de participación en los procesos de discernimiento y consulta en la toma de decisiones. Esta función de consulta -que debe ser revalorizada y valorada- no supone una invasión en las competencias de los Pastores o en su función propia de gobierno, sino que, como explicita el documento de la CTI, resaltando la clarificadora distinción entre el decision-making y el decision-taking, constituye «una distinción de competencias en la reciprocidad de la comunión» ${ }^{19}$.

En esta línea, el c. 228.2 reconoce expresamente la capacidad de los laicos para asesorar a los pastores y formar parte de los consejos instituidos; $y$, de hecho, el ordenamiento canónico abre la puerta a una significativa participación de los laicos en importantes órganos colegiados de gobierno, como son, a nivel diocesano, los Consejos de Asuntos Económicos del c. 492 -que gozan de muy importantes atribuciones (cc. 1277 y 1292) - y el Consejo Pastoral, en el que resulta obligatoria la inclusión de laicos (c. 512); y, a nivel parroquial, el Consejo Pastoral (c. 536) y el Consejo de Asuntos Económicos parroquial (c. 537). La participación de los laicos en estos órganos colegiados refleja la sinodalidad y tiene como fundamento la participación y corresponsabilidad del laicado en el gobierno de la Iglesia, en sus distintos niveles ${ }^{20}$, si bien, con frecuencia, estos consejos solo tienen una función consultiva.

A mi juicio, el reconocimiento legal del derecho-deber de opinión de todos los fieles recogida en el c. 212 permite sacar algunas consecuencias relevantes de cara a la profundización en la dimensión y vivencia sinodal de la Iglesia.

19 El texto continúa aclarando que «el proceso sinodal se debe realizar en el seno de una comunidad jerárquicamente estructurada. En una Diócesis, por ejemplo, es necesario distinguir entre el proceso para elaborar una decisión (decision-making) mediante un trabajo común de discernimiento, consulta y cooperación, y la decisión pastoral (decision-taking) que compete a la autoridad del Obispo, garante de la apostolicidad y catolicidad. La elaboración es una competencia sinodal, la decisión es una responsabilidad ministerial. Un ejercicio pertinente de la sinodalidad debe contribuir para articular mejor el ministerio del ejercicio personal y colegial de la autoridad apostólica con el ejercicio sinodal del discernimiento por parte de la comunidad»: CTI, La sinodalidad en la vida y misión de la Iglesia, n. 69.

20 A. Ciudad Albertos, Actuales expresiones canónicas de sinodalidad, Scripta Theologica 48 (2016) 707-730. 


\subsection{Reconocimiento del carácter fundamental y constitucional del derecho-deber de los laicos a expresar la propia opinión en cuestiones eclesiales}

El pleno reconocimiento y actuación de este derecho fundamental del c. 212 ayudaría a superar algunas interpretaciones "paternalistas" de esta participación de los laicos en la vida y misión eclesial. Aunque será necesario regular el alcance, modo y límite de la misma, debería partirse de la convicción de que la intervención de los laicos -según su propia competencia, formación, etc.- no es algo gracioso, que puede concederse o no, por parte de la autoridad; tampoco debería estar necesariamente sometido a una "invitación" previa y expresa por parte de la autoridad jerárquica, lo que de algún modo fomenta y perpetúa la pasividad laical en su implicación en la misión de la Iglesia. Desde la conciencia de los derechos-deberes derivados del Bautismo, que vienen recogidos por el legislador como derechos fundamentales y constitucionales de todo fiel, debe afirmarse que el reconocimiento codicial de este derecho de opinión de los fieles supone, por tanto, que los laicos pueden legítimamente, de modo no solo respetuoso, sino con verdadera vocación de servicio eclesial, hacer oír su voz -aunque sea crítica- sobre las cuestiones eclesiales, sin que deba limitarse esta posibilidad por falta de cauces articulados para hacerlo ni por exagerados temores a romper la unidad de la Iglesia. La comunión eclesial no es uniformidad despersonalizante ni asentimiento acrítico, ni puede considerarse irreverente ni rompedora de la unidad eclesial la manifestación de la propia opinión, aunque pueda ser divergente de la de la autoridad, especialmente si la opinión está sólidamente argumentada y se hace desde el respeto y la vocación eclesial.

$\mathrm{Y}$ aunque algunos autores han criticado, no sin razón, que se echaba en falta que la ley detallase cauces concretos y accesibles de ejercer este derecho de opinión, de modo que no se quedase en un principio vacío de contenido ${ }^{21}$, hay iniciativas recientes que resultan esperanzadoras en este sentido, como el reconocimiento expreso, en la nueva regulación legal del Sínodo de los Obispos, del derecho de los

21 J. M. Díaz Moreno, Los fieles cristianos..., cit., 169. 
fieles -individual o asociadamente- de dirigirse directamente a la Secretaría del Sínodo para exponer sus peticiones u opiniones sobre el tema a discutir ${ }^{22}$.

\subsection{Conveniencia de una revalorización de la función consultiva}

Aunque no faltan voces tendentes, en aras de un mayor ejercicio de la sinodalidad, a atribuir a algunos de los consejos y colegios previstos en el derecho -también a los constituidos por clérigos- funciones deliberativas ${ }^{23}$, ello no está exento de importantes dificultades, tanto constitucionales -atinentes a la específica misión de la Jerarquía en la Iglesia-como también de oportunidad y eficacia, pues el gobierno ordinario y habitual de la Iglesia, sea particular o -más aún- universal, no sería viable en un modelo deliberativo establecido con carácter general ${ }^{24}$. A modo de ejemplo, cabe citar que, pese a estar previsto en el derecho, en el más de medio siglo de existencia del Sínodo de los Obispos, y pese a su actual renovación, nunca se ha visto oportuno atribuir potestad deliberativa al mismo; y, obviamente, mucho más complejo sería articular, de modo ordinario, una forma de gobierno eclesial plenamente colegial y deliberativa.

En este sentido, y sin perjuicio de poder ampliar en algún caso la capacidad deliberativa de algunos consejos, sí sería necesario, a mi juicio, revalorizar y resaltar la importancia de esta función de consulta (decision-making) en la toma de decisiones por parte de la autoridad (decision-taking) ${ }^{25} \mathrm{y}$, sobre todo, aplicarla bien, lo que exigirá establecer procedimientos que favorezcan el desarrollo de los debates y el trabajo en común, fomentando, desde este espíritu sinodal, la participación ac-

22 Con la finalidad de «convertirse en un medio de escucha de todo el Pueblo de Dios», Episcopalis Communio no solo se establece el deber de los Obispos de hacer llegar los cuestionarios previos a todo el Pueblo de Dios, incluidos los laicos, y tramitar sus respuestas (E.C., n. 6), sino también reconoce, en el artículado, el derecho de los fieles -individual o asociadamente- de enviar directamente sus contribuciones (art. 7.2).

23 Cfr. D. Vitali, I soggetti della sinodalità alla luce dell'ecclesiologia del Concilio Vaticano II, en L. Baldisseri (ed.), A cinquant'anni dall'Apostolica Sollicitudo..., cit., 183-185.

24 Comparto, en este sentido, las acertadas reflexiones de A. VIANA, Sinodalidad y Derecho canónico, cit., 699-701.

25 CTI, La sinodalidad en la vida y misión de la Iglesia, nn. 67-68. 
tiva y dialogante de todos los consultados, lejos de rutinas y formalismos, pero también de actitudes impositivas y descalificatorias de los que mantienen otra opinión, intentando llegar a un consenso con espíritu de servicio y voluntad de diálogo, en un espíritu de comunión. Pero también exigirá, por parte de la autoridad, un real aprecio y valoración de la función consultiva, teniendo una actitud de recepción y escucha de lo que expresen los fieles consultados, y respetando los requisitos mínimos de esta función consultiva, pues, en ocasiones, especialmente en el plano diocesano, se confunde la consulta-que debe ayudar a formar la propia decisión- con la comunicación al consejo respectivo de una decisión previamente tomada por la autoridad ${ }^{26}$; en otras ocasiones, quizás en aras de una mayor rapidez, no se observan las consultas -a los órganos especializados o incluso a las Iglesias particulares- previstas por el derecho para la redacción de las leyes y textos normativos ${ }^{27}$, etc.

26 La Signatura Apostólica ha estimado, en ocasiones, el recurso contra decisiones episcopales tomadas sin la preceptiva consulta al Consejo presbiteral, cuando se prueba que el Obispo no consultó, sino que se limitó a informar al Consejo de una decisión previamente tomada: A. VIANA, Consultar no es informar de una decisión ya tomada. Comentario de la sentencia de la Signatura Apostólica de 27 de noviembre de 2012, Ius Canonicum 55 (2015) 763-767.

27 Resulta significativo que importantes leyes que han modificado profundamente el ejercicio de la potestad episcopal, como el M.P. Come una madre amorevole, no han incluido, en su proceso de elaboración, consultas a las Iglesias particulares ni a las Conferencias Episcopales, pese a estar dicha consulta prevista en la constitución apostólica Pastor Bonus, art. 26.1: A. Viana, Sinodalidad y Derecho canónico, cit., 690, nota 13. En otras ocasiones, como la reforma procesal establecida en los M.P. Mitis Iudex Dominus Iesus y Mitis et Misericors Iesus, que modifican profundamente las competencias de los Obispos en las causas de nulidad matrimonial, se constata que, si bien la reforma procesal surgió en el contexto del Sínodo sobre la Familia y en respuesta a algunas inquietudes expuestas en el aula sinodal, no se observaron sin embargo las consultas, previstas en la ley, a los órganos especializados de la Curia Romana -en concreto, al Pontificio Consejo de Textos Legislativos- lo que provocó algunas deficiencias, ambigüedades y dudas en el texto legal, que hubieron de ser posteriormente salvadas por un Rescripto ex audientia pontificis de 7 de diciembre de 2015 y que ha dado lugar a numerosas consultas al PCTL: W. L. DANIEL, An Analysis of Pope Francis' 2015 Reform of the General Legislation governing Causes of Nullity of Marriage, The Jurist 75 (2015) 430-437; C. PEÑA, La reforma de los procesos canónicos de nulidad matrimonial: el motu proprio 'Mitis Iudex Dominus Iesus', Estudios Eclesiásticos 90 (2015) 621-682; etc. 


\subsection{Un supuesto especial: el papel de los teólogos y canonistas}

Dentro de la vocación sinodal del entero Pueblo de Dios y del derecho fundamental de manifestar la propia opinión, presta un servicio específico el carisma de la teología ${ }^{28}$, en el que también los laicos tienen una voz propia y contribuciones que aportar. En efecto, tras siglos de monopolio clerical en campos tan destacados como el estudio y enseñanza de las ciencias sagradas, se reconoció con toda amplitud a los laicos, en el c. 229, tanto el derecho-deber a la formación en la doctrina cristiana $(\$ 1)$, a efectos de poder vivir conforme a ella y ejercer adecuadamente el apostolado, como el derecho a estudiar ciencias sagradas y a obtener grados académicos en universidades o facultades eclesiásticas y en los institutos de ciencias religiosas $(\$ 2)$, así como, una vez obtenida esta formación superior, la capacidad de enseñar ciencias sagradas (\$3), tanto en facultades eclesiásticas -donde dicha posibilidad se aplica con diferente amplitud, observándose aún algunas reticencias en algunos ámbitos- como incluso en seminarios, a tenor de la amplia redacción del c. 229 y de la ausencia de cualquier disposición contraria en el c. 253, si bien, en la formación de los candidatos al sacerdocio, la misma normativa de desarrollo establece como excepcional el nombramiento de profesores laicos ${ }^{29}$.

28 Así lo destaca expresamente el documento de la Comisión Teológica Internacional, afirmando que «en la vocación sinodal de la Iglesia, el carisma de la teología está llamado a prestar un servicio específico mediante la escucha de la Palabra de Dios, la inteligencia sapiencial, científica y profética de la fe, el discernimiento evangélico de signos de los tiempos, el diálogo con la sociedad y las culturas al servicio del anuncio del Evangelio (...) La sinodalidad eclesial compromete también a los teólogos a hacer teología en forma sinodal, promoviendo entre ellos la capacidad de escuchar, dialogar, discernir e integrar la multiplicidad y la variedad de las instancias y de los aportes»: CTI, La sinodalidad en la vida y misión de la Iglesia, n. 75.

29 En efecto, la normativa de desarrollo contempla con carácter bastante restrictivo esta posibilidad: así, la Ratio Fundamentalis Institutionis Sacerdotalis, de 6 de enero de 1970, de la Congregación para la Educación Católica, afirmaba que «para las disciplinas sagradas, los profesores deben ser generalmente sacerdotes» (n. 33). En la reciente Ratio, del pontificado de Francisco, se anima a la presencia de la mujer y de los laicos en el proceso formativo del Seminario (nn. 143, 151), aunque se sigue considerando «preferible que la mayoría del cuerpo docente esté constituido por presbíteros» (n. 143): CONGREGACIÓN PARA EL CLERO, Ratio Fundamentalis Institutionis Sacerdotalis, de 8 de diciembre de 2016, Ciudad del Vaticano 2016. 
La actividad docente de los teólogos $-\mathrm{y}$ de los canonistas ${ }^{30}$ - laicos supone una participación de estos en el munus docendi de la Iglesia, en cuanto que, en su caso, los laicos reciben la missio canonica o mandato para ejercer en nombre de la Iglesia esta concreta función eclesial, contribuyendo de este modo al ejercicio de la sinodalidad ${ }^{31}$. Asimismo, su labor investigadora, profundizando, en el caso de los teólogos, en los misterios de la fe, en el discernimiento de los signos de los tiempos y en el diálogo con las culturas, así como, en el caso de los canonistas, articulando vías de concreción normativa -eficaces, eclesiales y justas- de los avances teológicos, puede contribuir de modo decisivo -al igual que la de sus compañeros clérigos- a la misión evangelizadora de la Iglesia. En este sentido, sería conveniente que, en el contexto del reconocimiento del derecho a prestar su opinión especializada a los Pastores (c. 212.3) y del derecho a la libertad de investigación teológica/canónica y a la prudente manifestación de sus resultados (c. 218), se articularán vías concretas, habituales y efectivas de diálogo y colaboración con los Pastores.

\section{Participación de los laicos en El ejercicio DE LA FUNCIÓN DE GOBIERNO EN LA IGLESIA}

Además de los cauces, ya señalados, de consulta y expresión a los Pastores de la propia opinión en materias atinentes a la vida de la Iglesia, el derecho canónico reconoce a los laicos un amplio campo de actuación no solo en aquellos ámbitos referidos directamente a la dimensión secular del laico, a su actuación ante las realidades temporales, sino también en su actuación ad intra de la misma Iglesia, afirmando su

30 Personalmente, considero extensible lo dicho de los teólogos a los canonistas, en cuanto que el Derecho Canónico -también integrante de las ciencias sagradas- puede contribuir, desde su especificidad, a la mejor aplicación y concreción de las percepciones teológicas y eclesiológicas.

31 Además de esta específica colaboración de teólogos y canonistas en el munus docendi, el Código prevé una amplísima capacidad de iniciativa y actuación a todos los laicos en el anuncio evangélico, reconociendo que pueden «ser llamados a cooperar con el Obispo en el ejercicio del ministerio de la palabra» (c. 759), tanto en la catequesis (c. 776), como en la predicación (c. 766) -exceptuando la homilía, reservada a los ministros ordenados (c. 767.1) - , en la actividad misionera (c. 785), en los medios de comunicación social (c. 822) y en las instituciones docentes (escuelas y universidades), aparte de su insustituible misión en la educación católica de los hijos (c. 793). 
capacidad para ocupar cargos y funciones tradicionalmente reservadas a los clérigos, de modo que podrán cooperar activamente en el ejercicio de la función de gobierno (munus regendi). Así lo recoge -no sin cierta ambigüedad, fruto de tensiones doctrinales- el c. 129.2, que admite la posibilidad de que los laicos cooperen en el ejercicio de la potestad de régimen a tenor del derecho ${ }^{32}$, y ratifica, aún con mayor claridad, el importante c. 228.1, que reconoce con toda amplitud la capacidad de los laicos tanto para desempeñar encargos eclesiales como para ocupar oficios eclesiásticos propiamente dichos, esto es, para ser titulares de cargos establecidos establemente en orden a un fin espiritual, conforme a la definición del c. 145.

Este reconocimiento general de la capacidad de los laicos para desempeñar oficios eclesiásticos -que lleva aparejado el correlativo deber de formarse adecuadamente para prestar ese servicio a la Iglesia (c. 231)y cooperar en el munus regendi supone dar carta de naturaleza a la participación responsable de los laicos en la misión de la Iglesia, y constituye un reflejo excelente de la sinodalidad, pues, a mi juicio, esta no se realiza solo dando consejo u opinión esporádica u ocasional sobre algunas materias, sino también colaborando de modo estable en aquellos órganos o estructuras de gobierno que ayudan a la autoridad jerárquica en el ejercicio sinodal del gobierno ordinario, como son la curia diocesana o, a nivel universal, la curia romana.

32 A esta redacción, algo ambigua, del c. 129, se llegó tras notables discusiones en la comisión redactora del Código, al estar de fondo la polémica doctrinal entre la Escuela de Munich -que refiere toda potestad de régimen al orden sagrado- y la Escuela romana, que, afirmando el origen sacramental -basado en el orden sagrado- de la potestad en la Iglesia, admite sin embargo la capacidad de los laicos -derivada de su bautismo- de ser nombrados para cargos que supongan el ejercicio de jurisdicción, como muestra la milenaria historia de la Iglesia. Consultada expresamente la Congregación de la Doctrina de la Fe, en fecha 12 de marzo de 1976, sobre esta cuestión de si los laicos podían ser admitidos a oficios que supusieran ejercicio de la jurisdicción (pues la duda había surgido en varias de las comisiones redactoras de los diversos libros del Código), la Congregación, en su Respuesta de 8 de febrero de 1977, estableció el principio de que, dogmáticamente, los laicos solo están excluidos de aquellos oficios que sean intrínsecamente jerárquicos, correspondiendo a la ley determinar qué otros oficios podían desempeñar. Puede encontrarse tanto el texto de la cuestión, como la respuesta de la CDF, en Pontificio Consejo para la Interpretación DE TeXtos Legislativos, Acta et documenta PCCICIR. Congregatio plenaria diebus 20-29 octobris 1981 habita, LEV, Ciudad del Vaticano 1991, 37. 
Así lo destaca, con acierto, el documento de la Comisión Teológica Internacional, que afirma la dimensión sinodal de la curia diocesana y de «los diversos organismos destinados a coadyuvar, de forma permanente, en el ministerio del Obispo en la ordinaria guía pastoral de la diócesis», presentando la curia diocesana y estos organismos como «ámbitos permanentes de ejercicio y promoción de la comunión y la sinodalidad» ${ }^{33}$. En cuanto al gobierno de la Iglesia universal, el documento acentúa que «la Curia Romana, que por su naturaleza está íntimamente relacionada con la colegialidad episcopal y con la sinodalidad eclesial, ha sido establecida al servicio permanente del ministerio del Papa a favor de la Iglesia universal. Al ordenar que sea reformada a la luz de la eclesiología de comunión, el Concilio Vaticano II puso el acento sobre algunos elementos aptos para favorecer el incremento de la sinodalidad, entre los cuales está la inclusión de Obispos diocesanos para "comunicar con toda exactitud al Sumo Pontífice el pensamiento, los deseos y las necesidades de todas las Iglesias", y la consulta a los fieles laicos de forma que también ellos tengan su cometido conveniente en las cosas de la Iglesia» ${ }^{34}$.

Esta posibilidad de participación de los laicos en la función de gobernar (munus regendi) alcanza, en diverso grado y medida, tanto a la función legislativa -en la que su incidencia es menor ${ }^{35}$ - como a las funciones ejecutiva y, de modo muy especial, judicial, siendo en este ámbito donde la participación de los laicos resulta más destacable y significativa.

Respecto a la función ejecutiva, el Código abrió varias vías de colaboración de los laicos, que han ido aplicándose paulatinamente, en diversa medida, tanto a nivel particular -donde los laicos pueden desempeñar, nombrados por el Obispo, relevantes cargos y oficios eclesiásticos, entre

\footnotetext{
CTI, La sinodalidad en la vida y misión de la Iglesia, n. 80.

Ibid., n. 102.

35 Sin perjuicio de que pudieran articularse vías para una mayor participación de los laicos en los procesos de elaboración de las leyes eclesiásticas, hoy por hoy, la reserva de la función legislativa ordinaria al Obispo o al Romano Pontífice hace que la intervención de los laicos en este campo quede reducida, a nivel universal, a la hipotética posibilidad de ser llamados a participar en el Concilio Ecuménico, con voz y voto, o con voz pero sin voto, según determine el Romano Pontífice o el mismo Concilio (c. 339.2). A nivel de Iglesias particulares, los laicos podrán ser invitados a participar en los Concilios particulares, sean plenarios o provinciales, aunque gozarán únicamente de voto consultivo (c. 443.4 y 6); asimismo, cabría citar -pese a su carácter solo consultivo- la participación de los fieles laicos en el Sínodo diocesano, conforme al c. $463.1 .5^{\circ}$ y 2 .
} 
ellos los de canciller y notario de la curia (cc. 482-484), ecónomo diocesano (c. 494), censor de libros (c. 830.1), administradores de personas jurídicas públicas eclesiásticas (cc. 1279 y 1280), etc.- como a nivel de Iglesia universal ${ }^{36}$, observándose en los últimos tiempos -en el contexto del proceso de reforma de la Curia Romana- un cierto incremento del número de laicos que participa de algún modo en el ejercicio de la potestad de gobierno, desempeñando cargos u oficios eclesiásticos en la Curia Romana ${ }^{37}$.

Otro ejemplo muy habitual del ejercicio de la función de régimen por miembros no ordenados se da en el ámbito de la vida consagrada, tanto femenina como, incluso, en ocasiones, masculina. En este ámbito, se observa cómo superioras religiosas o religiosos varones no ordenados desempeñan verdaderas funciones de gobierno que, aunque limitadas al propio instituto, suponen de hecho el ejercicio de potestad de régimen: así ocurre con los superiores y los capítulos de los institutos religiosos, a los que el Código reconoce que ejercen potestad ${ }^{38}$. En este

36 A nivel universal, la regulación codicial abrió la puerta a que los laicos puedan ser nombrados legados del Romano Pontífice (c. 363.1) -aunque de hecho no se aplicao delegados y observadores de la Santa Sede ante organismos o conferencias internacionales (c. 363.2), así como a cierta participación (como consultores o desempeñando determinados oficios) en los Dicasterios de la Curia Romana, si bien esta cuestión se reguló extracodicialmente, en la c.a. Pastor Bonus de Juan Pablo II sobre la curia romana, de 28 de junio de 1988.

37 A la espera de la definitiva promulgación de la anunciada constitución apostólica Praedicate Evangelium de reforma de la Curia Romana, se han producido en la misma, aunque sigue siendo un ámbito mayoritariamente clerical, un cierto incremento de nombramientos de fieles laicos como miembros - no solo como consultores- de dicasterios romanos, incluso asumiendo cargos de responsabilidad: así ocurre en el Dicasterio para el Servicio del Desarrollo Humano Integral, en cuya regulación se prevé que el Secretario y el Subsecretario pueden ser laicos (art. 2.1 de sus Estatutos), o el Dicasterio para los laicos, familia y vida, en el que, además de esta posibilidad, sus Estatutos (art. 2) exigen que haya al menos dos Subsecretarios laicos (en la actualidad, ambas subsecretarias son laicas); el Dicasterio para la comunicación, que tiene al frente un Prefecto laico; la participación de laicos como miembros en el Consejo para la Economía, la Pontificia Comisión para la protección de los menores, la Pontificia Comisión de Estudio y Guía para los Asuntos Económicos y Administrativos, el Instituto para las Obras de Religión, etc.

38 De hecho, si bien el c. 596 establece una imprecisa distinción entre la potestad ejercida en todos los institutos $(\$ 1)$ y la ejercida en los institutos clericales de derecho pontificio, a los que se reconoce que tendrán «además potestad eclesiástica de régimen» $(\$ 2)$, lo cierto es que, sin perjuicio de lo que disponga el derecho propio, las funciones que el Código reconoce a todos los Superiores, sean clérigos o laicos, son 
sentido, cabe señalar que, en la reciente reforma de la vida contemplativa femenina propiciada por el papa Francisco ${ }^{39}$, se ha producido un reforzamiento de las funciones de la priora -considerada superiora mayor- de un monasterio sui iuris. Por otro lado, incluso en los institutos religiosos clericales, que deben estar dirigidos por clérigos (c. 588), consta que la Santa Sede ha concedido -con carácter excepcional y temporal (nombramientos ad casum) ${ }^{40}$, o incluso con carácter general al aprobar las Constituciones de algunos Institutos- que puedan los hermanos laicos ser superiores locales e incluso superiores mayores, lo cual abre la puerta a la posibilidad de una ampliación de las funciones de gobierno de los no ordenados en el ámbito de la vida religiosa ${ }^{41}$.

prácticamente las mismas -salvo la concesión de la exclaustración-e incluyen algunas tan relevantes como establecer formalmente divisiones internas del Instituto (c. 581), que en caso de ser provincias serán automáticamente personas jurídicas públicas (c. 638.1); erigir formalmente casas (c. 609.1), que son automáticamente personas jurídicas públicas, así como suprimir casas que habían sido formalmente erigidas (c. 616.1); representar a la persona jurídica pública (c. 118) en actos de administración que afectan a bienes eclesiásticos (cc. 634.1 y 635.1); admitir miembros a la profesión temporal y perpetua (cc. 656.3 y 658); emitir un indulto de exclaustración por hasta tres años (c. 686.1); permitir a un miembro de votos temporales dejar el Instituto (c. 688.2); emitir el decreto de dimisión, incluso para miembros de votos perpetuos (c. 699.1); etc. Como destacó en su momento una autora, a la vista de esta regulación común a todos los institutos, no parece razonable afirmar que estos actos, cuando sean puestos por superiores clérigos, serán actos derivados de la potestad de régimen que tiene su origen en el orden sagrado, mientras que cuando sean puestos por Superiores religiosos no ordenados -varones o mujeres- responderán a otro tipo de potestad eclesiástica no especificada: E. McDonougH, Furisdiction exercised by non-ordained member in Religious Institutes, CLSA Proceedings 58 (1996) 306.

39 Francisco, Constitutio apostolica Vultum Dei Quaerere. De vita contemplativa monialium, 20 junio 2016: AAS 108 (2016) 835-861; CIVCSVA, Cor Orans. Instrucción aplicativa de la Constitución apostólica Vultum Dei quaerere sobre la vida contemplativa femenina (15V-2018), Ciudad del Vaticano 2018.

40 Así ocurrió, p.e., con el nombramiento de un Hermano camilo ad instar vicarii-vicario provincial- tras la renuncia del superior provincial: Ecclesia, n. 3745, 20 de septiembre de 2014, 1353.

41 Sobre la problemática jurídica de estas concesiones de facultades de gobierno a hermanos laicos en los institutos clericales, T. BAHILLO, Presencia de religiosos laicos en institutos clericales. Institutos mixtos, ¿posibilidad real o vía sin salida?, Estudios Eclesiásticos 89 (2014) 675-699. Como señala el autor, el hecho de que, aunque sea por concesión de la Santa Sede, miembros no ordenados (laicos) ejerzan de facto jurisdicción incluso en los institutos clericales indica que no es algo imposible, con independencia de su mayor o menor oportunidad (698). 
Igualmente, también está muy relacionada con el ejercicio sinodal de la función de gobierno, entendida en un sentido amplio, la posibilidad -prevista en el c. 517.2- de que el Obispo, en caso de escasez de sacerdotes, pueda encomendar el ejercicio de la cura pastoral de la parroquia tanto a un laico como a una comunidad como a un diácono, siendo significativo que no se establezca una explícita preferencia por estos últimos, pese a su carácter ordenado ${ }^{42}$.

Aún más amplia es la posibilidad de participación de los laicos en el ejercicio de la función judicial integrante del munus regendi. En este sentido, ya la regulación codicial estableció en su momento que los laicos -debidamente formados- podían desempeñar prácticamente todos los oficios y cargos en los tribunales eclesiásticos, excepto los de Vicario judicial y Vicario judicial adjunto (c. 1420.4) y el de juez único (c. 1421.1). En concreto, el Código de 1983 abrió la puerta, sin limitación ningu$\mathrm{na}^{43}$, al nombramiento de laicos para los cargos de Secretario General o Moderador de la Cancillería del Tribunal, notario (c. 1437), asesor del juez único (c. 1424), auditor no juez (c. 1428), así como los ministerios públicos de Defensor del vínculo y Promotor de justicia (c. 1435), e incluso, aunque con limitaciones, Juez.

Especial relevancia tiene el reconocimiento legislativo de la posibilidad de nombrar a los laicos -varones o mujeres- jueces eclesiásticos, puesto que, como se reconoció en el proceso codificador, la potestad ejercida por el juez laico es verdadera jurisdicción, igual a la de los jueces clérigos ${ }^{44}$; de hecho, cabe destacar que todos los votos emitidos en el colegio de jueces -sean de clérigos o de laicos- tienen el mismo valor de cara a la decisión definitiva.

42 En cualquier caso, conforme al mismo canon, las potestades propias del párroco y la dirección de la actividad pastoral deberán ser encomendadas a un sacerdote: F. HEREDIA ESTEBAN, La parroquia "in solidum": una respuesta a nuevas necesidades, Revista Española de Derecho Canónico 66 (2009) 551-585; A. VIANA, Atención de parroquias en situaciones de escasez de clero. El supuesto del canon 5172 del CIC, Telmus: Anuario del Instituto Teológico San José (2010) 83-105.

43 Ya con anterioridad a la promulgación del Código, los laicos podían actuar como peritos, abogados y procuradores, figuras a las que el nuevo Código añadió la de los patronos estables (c. 1490).

44 Así, a la pregunta de si los jueces seglares ejercen jurisdicción individualmente o por formar parte del Colegio, la Pontificia Comisión para la revisión del Código contestó que la ejercen por su propio derecho: Communicationes 3 (1971) 187. 
Aunque esta posibilidad de los jueces laicos venía regulada en el Código con matices algo restrictivos, al exigir una situación de necesidad, el permiso previo de la Conferencia Episcopal y la actuación de un único juez laico en un tribunal colegiado de tres jueces (c. 1421.2), muchas Conferencias Episcopales fueron implantando la figura del juez laico ${ }^{45}$. Por su parte, la reciente reforma de los procesos de nulidad matrimonial realizada por el papa Francisco avanza en esta línea, eliminando las limitaciones anteriormente previstas en el texto codicial y permitiendo directamente a cada Obispo, sin necesidad del permiso previo de la Conferencia Episcopal, nombrar hasta dos jueces laicos para que formen parte del tribunal colegial de tres jueces ${ }^{46}$.

El reconocimiento legal de esta figura del juez laico, prevista ya tras el Concilio en el M.P. Causas matrimoniales de Pablo VI (1971), aunque con un carácter fuertemente excepcional y reservada a varones, y paulatinamente normalizada por la legislación y praxis de Juan Pablo II y, recientemente, Francisco ${ }^{47}$, tiene especial relevancia de cara a una

45 Así ocurría en la inmensa mayoría de países europeos, en los que los Obispos nombraron jueces a laicos, varones y mujeres, para integrar su tribunal y dar respuesta, en su nombre, a las demandas de los fieles. Especialmente relevante resultaba el caso de Italia, siendo significativo que el tribunal del Vicariato de la Urbe, de Roma, tuviese, desde hace casi tres décadas, varios jueces laicos, la mayoría mujeres. En este sentido, España aparecía como una excepción entre los países de nuestro entorno, al ser uno de los pocos en que la Conferencia Episcopal se resistía a autorizar el nombramiento de jueces laicos: C. PEÑA, La aplicación de la Instrucción Dignitas Connubii en España: valoración y sugerencias de mejora tras 10 años de vigencia, Periodica de re canonica 104 (2015) 517-543.

46 Francisco, Litterae Apostolicae Motu Proprio datae Mitis Iudex Dominus Iesus quibus canones Codicis Iuris Canonici de causis ad matrimonii nullitatem declarandam reformantur, de 15 de agosto de 2015: AAS 107 (2015) 958-970. No obstante, se mantienen aún en Mitis Iudex algunas limitaciones a la participación laical -a mi juicio, carentes de fundamento- en la regulación positiva de estos cánones, como la reserva al juez clérigo de la presidencia del tribunal colegial (c. 1672.3), o la imposibilidad de un colegio formado solo por laicos o de que el laico actúe como juez único: M. J. ARrobA CONDE, Giusto processo e peculiarità culturali del processo canonico, Aracne, Roma 2016, 56, nota 38; G. BonI, La recente riforma del processo di nullità matrimoniale. Problemi, criticità, dubbi (parte terza), Stato, Chiese e pluralismo confessionale 11 (2016) 17; J. LLOBELL, I processi matrimoniali nella Chiesa, EDUSC, Roma 2015, 116; F. S. REA, L'esercizio della potestà giudiziaria del fedele laico..., cit., 36-55, etc.

47 Debe destacarse, no obstante, que esta aceptación del juez laico se da en el ámbito de la Iglesia particular, pues los Tribunales Apostólicos integrantes de la Curia Romana (Signatura Apostólica, Rota Romana y Penitenciaría Apostólica) se rigen por leyes 
cuestión siempre subyacente o problemática en cualquier aproximación al tema de la asunción de oficios eclesiásticos por parte de laicos, como es la de la vinculación entre el orden sagrado y la potestad de régimen o gobierno ${ }^{48}$. En este sentido, más allá de los debates doctrinales de escuela sobre el fundamento y límites de la potestad de régimen, tanto la ley eclesial como la praxis mantenida de forma continua por los últimos pontífices respecto a una figura -la del juez laico- que, ciertamente, ejerce jurisdicción (iuris-dictio) en virtud del oficio, muestra la posibilidad y la pertinencia de que los laicos participen responsablemente, presupuesta su formación y el explícito encargo episcopal (missio canonica), en el ejercicio de la potestad de régimen ${ }^{49}$.

En cualquier caso, la insistencia en la jurisdicción que ejerce el juez -laico o clérigo- en virtud de su oficio no debe ser interpretada como una vuelta a concepciones eclesiológicas pasadas. Al contrario, también en el ámbito judicial se observa, con especial fuerza, el desplazamiento conceptual que transita de la afirmación de la potestad de jurisdicción a

propias, mucho más restrictivas que el derecho universal para la incorporación de laicos, especialmente como jueces. Se trata de una cuestión que convendría revisar, al menos respecto a la Rota Romana (en este sentido F. S. REA, L'esercizio della potestà giudiziaria del fedele laico, cit., 56-57).

48 Musselli destaca la relevancia del ejercicio de la función jurisdicional por laicos, afirmando que la misma representa «probabilmente, a tutt'oggi, la funzione più incisiva e più alta che un laico possa esercitare nel contesto ecclesiale, in un'ottica (...) che trascende l'usuale visione ministeriale del laicato e forse preclude a nuovi futuri orizzonti»: L. Musselli, Il giudice laico come "estensore" nei tribunali ecclesiastici, en M. VISMARa Missiroli - M. Madonna - A. Tira - C. E. Veralda (a cura di), Società civile e società religiosa tra diritto e storia. Scritti scelti, Wolters Kluver-Cedam, Padova 2016, 90.

49 Sobre el ejercicio de la jurisdicción por parte de los laicos, resultan de interés, entre otros, De participatione laicorum in exercitio potestatis regiminis, en PONTIFICIO CONSEJO PARA la INTERPRETACIÓn DE TeXTOS Legislativos, Acta et documenta PCCICIR..., cit., 35-97, 190-229 y 493-495 (especial interés tiene, en este sentido, la amplia intervención del Card. Ratzinger: ibid., 38-44); J. P. BEAL, The Exercise of the Power of Governance by Lay People: State of the Question, The Jurist 55 (1995) 52; J. BEYER, Iudex laicus vir vel mulier, Periodica de re canonica 75 (1986) 29-60; P. ERDÖ, Questiones de officiis ecclesiasticis laicorum, Periodica de re canonica 81 (1992) 185; J. H. PROvOST, Role of Lay Fudges, The Jurist 45 (1985) 333; A. P. TAVANI, I laici e la funzione giudiziaria, en AA. Vv., I soggetti nel nuovo processo matrimoniale canonico. Atti del XLVIII Congresso Nazionale di Diritto Canonico. Udine, 5-8 settembre 2016, Libreria Editrice Vaticana, Città del Vaticano 2018, 185-201; A. VIANA, El problema de la participación de los laicos en la potestad de régimen: dos vías de solución, Ius Canonicum 54 (2014) 603-638; etc. 
la acentuación del munus y de la ministerialidad, concibiéndose en la actualidad la estructura judicial como un servicio eclesial para hacer justicia, viniendo definida propiamente como un ministerium iustitiae ${ }^{50}$.

Esto es especialmente perceptible en la última reforma de los procesos de nulidad matrimonial realizada por el papa Francisco, que, además de surgir en un contexto eminentemente sinodal -en cuanto respuesta a los problemas y soluciones debatidas en el Sínodo Extraordinario sobre la Familia- pone fuertemente el acento en la necesidad de "conversión" de las estructuras eclesiásticas (en este caso, judiciales) y en la dimensión pastoral y misionera de los tribunales eclesiásticos, también llamados a formar parte de la "Iglesia en salida" ${ }^{51}$. En esta reforma, se produce una fuerte revalorización del papel del Obispo, que puede -e incluso, en algunos supuestos, debe- desempeñar su función de juzgar por sí mismo, aunque habitualmente lo hará por medio del tribunal por él constituido. Asimismo se observa, incluso en decisiones de mera técnica procesal, una decidida opción por criterios de sinodalidad y de colegialidad. Así, en relación con la sinodalidad, el legislador, previendo las dificultades que puede encontrar el Obispo para la constitución de su tribunal, amplía su libertad a la hora de nombrar los jueces, favoreciendo una mayor participación de todos los miembros del Pueblo de Dios con la necesaria formación; por otro lado, opta por favorecer el principio de colegialidad, manteniendo la preferencia por el tribunal colegial -aun constituido por una mayoría de laicos- frente al juez único (clérigo) ${ }^{52}$.

50 C. IZZI, I ministri di giustizia in genere (artt. 33-37), en P. A. BONNET - C. GULLO (a cura di), Il giudizio di nullità matrimoniale dopo l'Istruzione "Dignitas Connubii". Parte seconda: la parte statica del processo, Libreria Editrice Vaticana, Città del Vaticano 2007, 105.

51 M. J. ARRoba Conde, La pastoral judicial y la preparación de la causa en el motu proprio Mitis Iudex Dominus Iesus, en M. E. Olmos Ortega (ed.), Procesos de nulidad matrimonial tras la reforma del papa Francisco, Dykinson, Madrid 2016, 63-82; C. PEÑA, Il M.P. Mitis Iudex alla luce delle difficoltà sollevate dal Questionario presinodale e delle richieste emerse nei Sinodi sulla famiglia. Indagine Pregiudiziale o Pastorale, en Le Regole procedurali della Mitis Iudex Dominus Iesus. Linee guida per un'azione pastorale nel solco della giustizia, Libreria Editrice Vaticana, Città del Vaticano 2019, 11-28; C. PEÑA, Nueva regulación de las nulidades matrimoniales. Claves de lectura de una relevante reforma procesal, Sal Terrae 104 (2016) 257-269.

52 Solo en caso de imposibilidad, puede el Obispo diocesano decantarse por el tribunal unipersonal, mientras que el tribunal de segunda instancia debe ser necesariamente colegial (c. 1673). Remarca esta idea A. P. TAVANI, I laici e la funzione giudiziaria, cit., 193, nota 64. 
Con esta superación -al menos para las causas de nulidad, inmensa mayoría en la actividad de los tribunales eclesiásticos- de las limitaciones que el c. 1421 establecía para el nombramiento de jueces laicos, el M.P. Mitis Iudex favorece una mayor y más activa participación de los laicos en la potestad judicial, en el contexto de una estrecha colaboración entre clérigos y laicos, y de estos con el ministerio episcopal. El laico, en cuanto bautizado, participa del munus regendi y puede -al igual que los clérigos- ser llamado por el Obispo, Juez nato de la diócesis y verdadero titular de la potestad judicial, a colaborar, en función de su formación específica y su competencia, en el ministerium iustitiae, mediante la atribución (missio canonica) del oficio eclesiástico de juez en el tribunal del Obispo. La reforma procesal refuerza notablemente el papel -y la responsabilidad- del Obispo en su tribunal, dándole mayor libertad a la hora de discernir a quiénes debe encomendar la delicada labor de juzgar, en su nombre, los complejos casos matrimoniales que los fieles le plantean, decisión en la que, como destaca la práctica totalidad de la doctrina procesalista, la preparación técnica y las capacidades humanas requeridas para el adecuado cumplimiento del oficio deben pesar más que la condición, clerical o laical, del titular del mismo ${ }^{53}$.

A nuestro juicio, estos ejemplos de participación laical en la función de gobierno de la Iglesia ya de facto actuantes en la vida de la Iglesia -muy especialmente, aunque no solo, la figura del juez laicoapuntan a la conveniencia de seguir avanzando por este camino de normalización de la participación de laicos en el ejercicio y titularidad de oficios eclesiásticos en el ámbito de su competencia, contribuyendo, desde su específico ser y estar en la Iglesia y en el mundo, a una renovación sinodal de la vida y misión de la Iglesia y a una conversión de las estructuras eclesiales, haciéndolas menos clericales y aproximándolas a la sensibilidad y modo de expresión del Pueblo de Dios; en el caso de las mujeres, en concreto, potenciando que la Iglesia muestre al mundo un rostro más maternal. Obviamente, no se trata de "clericalizar" a los laicos, sino de que también los órganos de gobierno eclesiales reflejen, en su misma composición, la pluralidad de la Iglesia, integrando en ellos a

53 M. J. ARROBA CONDE - C. IZZI, Pastorale giudiziaria e prassi processuale nelle cause di nullità del matrimonio. Dopo la riforma operata con il Motu proprio Mitis Iudex Dominus Iesus, San Paolo, Cinisello Balsamo 2017, 58, nota 35. 
laicos que, desde su vivencia plenamente laical, puedan arrojar una luz nueva a los problemas pendientes y desarrollar de modo distinto -conforme a su competencia y preparación, pero también conforme a su sensibilidad y modo de ser- las tareas y funciones encomendadas.

\section{PARTICIPACión de los LaiCOS EN EL EJERCICIO DEL MUNUS SANTIFICANDI: LA PROBLEMÁTICA REGULACIÓN DE LOS MINISTERIOS LAICALES}

Aunque la sinodalidad parece hacer referencia más directamente al proceso de toma de decisiones o incluso a la forma de ejercer el gobierno, no cabe olvidar que tiene también una fundamental dimensión misionera y evangelizadora, en la que queda involucrado el entero Pueblo de Dios, llamado todo él -laicos incluidos- a participar activa y responsablemente también en la misión santificadora de la Iglesia.

A este respecto, cabe destacar que, tras el Concilio, también en el ámbito del munus santificandi de la Iglesia se ha ido reconociendo a los laicos un papel propio (c. 835), habiéndose ampliado muy significativamente su posibilidad de participación en la administración de los sacramentos y en el culto sagrado. No obstante, lo cierto es que esta apertura a un papel más activo de los laicos en la función de santificar parece derivar, no tanto de la convicción de la ministerialidad laical, sino más bien de razones de necesidad, en cuanto que la actuación del laico viene supeditada, en líneas generales, a la ausencia de clérigos, estableciéndose diversas trabas al ejercicio de estas funciones por los laicos.

En cualquier caso, frente a la rígida distinción entre funciones clericales y funciones laicales en épocas pretéritas, es digno de destacar que en la actual regulación canónica, prácticamente todas las funciones que el Concilio y el derecho conceptúa como propias del diácono -salvo la homilía en el contexto de la celebración eucarística ${ }^{54}$ - pueden

54 El c. 767.1 establece expresamente la reserva de la bomilía a los ministros ordenados, al disponer que «entre las formas de predicación destaca la homilía, que es parte de la misma liturgia y está reservada al sacerdote o al diácono». Esta prohibición fue reiterada firmemente en la Instrucción Ecclesiae de mysterio, de 15 de agosto de 1997, sobre la colaboración de los fieles laicos en el sagrado ministerio de los sacerdotes, que afirma además la derogación de cualquier norma anterior en sentido contrario (art. 3). 
ser desempeñadas, con diversos requisitos, por fieles laicos, varones o mujeres ${ }^{55}$.

Así, en relación con la administración de sacramentos, podrán los laicos ser designados ministros extraordinarios del Bautismo cuando se encuentre ausente o impedido el sacerdote o diácono (c. 861.2); ser ministros extraordinarios de la sagrada Comunión «donde lo aconseje la necesidad de la Iglesia y no haya ministros» (c. 910.2), así como administrar el viático, en caso de necesidad o con licencia al menos presunta del párroco (c. 911.2) ${ }^{56}$; ser ministros de la exposición del Sacramento, "en circunstancias peculiares", aunque solo para la exposición y reserva, sin bendición (c. 943). En cuanto a la celebración del matrimonio, los laicos, además de ser de suyo ministros de su propio matrimonio, podrá asistir como testigos cualificados, en nombre de la Iglesia, a la celebración de otros matrimonios, si bien esta posibilidad viene regulada de modo ciertamente restrictivo $^{57}$.

Respecto al culto sagrado, podrá un laico -varón o mujer- tanto presidir las oraciones litúrgicas y ejercitar el ministerio de la Palabra (c. 230.3) como presidir las exequias y ritos funerarios, si bien en ambos casos solo en el supuesto de ausencia de ministro ordenado ${ }^{58}$.

Es en este contexto de la participación de los fieles laicos en el $m u$ nus santificandi de la Iglesia donde, sin embargo, se produce una llamativa quiebra del principio de igualdad entre mujeres y varones laicos ${ }^{59}$,

55 C. PEÑA, ¿Diaconisas? Apuntes canónicos para la reflexión, Vida Nueva 2.989, 21-27 de mayo de 2016, 26-28; Diaconado femenino y ministerios: aportaciones canónicas para la reflexión teológica, en S. MARTíNEZ CANO - C. SOTO (ed.), Mujeres y diaconado. Sobre los ministerios en la Iglesia, Verbo Divino (Aletheia), en prensa.

56 De hecho, resulta muy relevante la contribución de religiosas y laicos comprometidos en este servicio, si bien la Instrucción de 1997 advierte de la necesidad de, en este apostolado de los enfermos, no inducir a confusión con «aquellos sacramentos cuya administración es propia y exclusiva del Obispo y del presbítero», haciendo referencia al sacramento de la Unción de enfermos: Instrucción, art. 9.

57 El c. 1112. 1 exige la concurrencia de varios requisitos para que el laico pueda "celebrar" matrimonios: situación de carencia de sacerdotes y diáconos en el territorio; voto favorable de la Conferencia Episcopal respecto a la posibilidad de delegación a laicos de la facultad de asistir al matrimonio; y licencia de la Santa Sede permitiendo la delegación a laicos.

58 Ordo exsequiarum, Praenotanda, n. 19.

59 Sobre la situación jurídica de la mujer en el derecho eclesial, entre otros, M. BLANCO, La mujer en el ordenamiento jurídico canónico, Revista General de Derecho Canóni- 
precisamente en la configuración de los ministerios laicales de lector y acólito, cuya institución como ministerios estables, mediante el rito litúrgico prescrito, queda reservada a los varones (c. 230.1), a pesar de reconocer el mismo canon que la mujer puede desempeñar -y, de hecho, así lo hace en muchas ocasiones- todas las funciones encomendadas a estos ministerios, sea por encargo temporal (c. 230.2) o por suplencia del ministro ordenado, en situaciones de ausencia o defecto de estos (c. 230.3).

Se trata de una quiebra de la paridad que afecta directamente al estatuto jurídico de los fieles laicos, todos iguales en virtud del bautismo, y que carece de fundamento desde el momento en que estos ministerios -anteriormente configurados como órdenes menores, previas a la recepción del diaconado y del sacerdocio- pierden su carácter clerical y son reconocidos en el postconcilio como ministerios laicales ${ }^{60}$, especialmente teniendo en cuenta que, paradójicamente, no se pone ninguna traba al ejercicio por parte de las mujeres de todas las funciones integrantes de dichos ministerios. En definitiva, aun afirmándose la capacidad femenina para desempeñar idénticas funciones eclesiales que los varones laicos, en este punto la vigente regulación refleja cierta reticencia a reconocer a las mujeres como titulares de un ministerio -incluso laical- instituido o estable dentro de la Iglesia.

Buena muestra de la conciencia eclesial respecto a la falta de fundamento de esta reserva de los ministerios laicales a los varones es el hecho de que el Sínodo de los Obispos de 2008 sobre la Palabra propusiera, en sus conclusiones finales, aprobadas por amplísima mayoría, la superación de esta distinción y la admisión de las mujeres al ministerio

co y Derecho Eclesiástico del Estado 20 (2009) 15 (www.iustel.com); M. Á. FÉLIX BALlesta, La mujer en el Derecho Canónico, en C. Melero (ed.), XV Fornadas de la Asociación Española de Canonistas en el XXV Aniversario de su fundación, UPSA, Salamanca 1997, 99-135; C. PEÑA, Status jurídico de la mujer en el ordenamiento de la Iglesia, Revista Española de Derecho Canónico 54 (1997) 685-700; C. PEÑA, Presencia de la mujer en la Iglesia desde la perspectiva jurídico-canónica, Confer 56 (2017) 401-414; etc.

La razón aducida para el mantenimiento de esta reserva al varón de estos ministerios es «la venerable tradición de la Iglesia», pero esta se basaba precisamente en el carácter clerical que poseían, en cuanto órdenes menores, antes del M.P. Ministeria Quaedam, por lo que no resulta coherente mantenerla tras su conversión en ministerios laicales. 
estable del electorado ${ }^{61}$. Lamentablemente, pese a esa aportación sinodal, lo cierto es que dicha petición no encontró acogida en la definitiva exhortación apostólica ni dio origen a una reforma de la regulación canónica, que permanece inalterada.

\section{Conclusiones}

El recorrido por todos los cauces de participación y corresponsabilidad de los laicos en la vida y misión de la Iglesia que abre la legislación y la praxis eclesial permite, a mi juicio, extraer algunas sugerencias para hacer efectiva la vocación sinodal de todo el Pueblo de Dios y, muy particularmente, del laicado:

Desde la afirmación tanto de la específica ministerialidad laical como de la necesidad de ir realizando progresivamente esta vocación sinodal, que aparece como fruto de la renovación conciliar y que promueve e integra la participación activa y responsable de todo el Pueblo de Dios en la vida y misión de la Iglesia, sería conveniente actuar esta dinámica sinodal en clave de capilaridad, de modo que impregnase toda la actuación eclesial, desde la activa intervención de los laicos en la vida de las parroquias a su participación normalizada en órganos consultivos y en estructuras eclesiásticas de servicio, tanto a nivel diocesano como universal.

El nombramiento de laicos -según su formación y competenciapara formar parte de consejos y órganos asesores, así como para el desempeño de oficios eclesiásticos en las curias diocesanas o en la misma Curia Romana permitiría que aportasen la específica mirada y estilo laical (también, en su caso, el "genio femenino", de que hablaba Juan Pablo II) en la actividad eclesial. En el contexto de la llamada a la «conversión -pastoral y misionera- de las estructuras eclesiásticas» a que exhorta constantemente el papa Francisco, conviene evitar «la tenta-

${ }^{61}$ La Proposición 17 presentada a Benedicto XVI, tras reconocer el papel de los laicos y de la mujer en la transmisión de la fe, concluía solicitando "que el ministerio del lectorado se abra también a las mujeres, de modo que se vea reconocido en la comunidad cristiana su rol de anunciadoras de la Palabra": http://www.vatican.va/roman_curia/synod/documents/rc_synod_doc_20081025_elenco-prop-finali_it.html\#Minister o_della_Parola_e_donne (consultado 30 de junio de 2017). 
ción de un excesivo clericalismo» que mantiene a los laicos no solo, como se reconoce en Evangelii Gaudium 102, al margen de las decisiones, sino también sin poder contribuir, con su aportación y estilo específicos, al buen funcionamiento de las estructuras eclesiales de gobierno, e, incluso, en su caso, a una mejor realización del munus santificandi en la Iglesia.

Desde el Kairós de la sinodalidad, es el momento de superar antiguas suspicacias y promover en todos los ámbitos la participación corresponsable del laicado en la vida y misión de la Iglesia. Esto exigirá, con carácter general, favorecer -o establecer, en su caso- vías eficaces de escucha y consulta al Pueblo de Dios en su conjunto y a los laicos en particular, individual o asociadamente, en la toma de decisiones, así como revalorizar la función consultiva y realizarla adecuadamente, sin perjuicio de seguir profundizando sobre la oportunidad de atribuir en algún caso funciones deliberativas a órganos consultivos.

Asimismo, exigirá favorecer la incorporación de laicos, según su competencia y preparación, al desempeño de oficios eclesiásticos en las curias diocesanas y en la misma Curia Romana, normalizando la presencia laical -ya ampliamente prevista en el derecho canónico- en estructuras de gobierno eclesial, pues la sinodalidad no se agota en la función consultiva, sino que se realiza también mediante la colaboración estable en aquellos órganos que ayudan a la autoridad en el ejercicio sinodal de las funciones ordinarias de gobierno. Tanto las exigencias derivadas del principio teológico de la sinodalidad, como los cauces abiertos por la legislación y la praxis eclesial, muestran la necesidad de no quedarse anclados en debates doctrinales ya superados, sino avanzar e implementar sin reticencias las posibilidades ya reconocidas por el mismo derecho para la participación de los laicos en el munus regendi, tanto en funciones ejecutivas como judiciales; pero será igualmente necesario profundizar críticamente en el fundamento y justificación de algunas limitaciones establecidas por ley positiva, especialmente las existentes para el pleno reconocimiento y capacidad de actuación de los jueces laicos. En definitiva, la renovada sensibilidad sinodal exige sacar todas las consecuencias de la dignidad y corresponsabilidad de todos los bautizados en la misión de la Iglesia, y reconocer con carácter general, en línea con el criterio establecido en su momento por la Congregación de la Doctrina de la Fe, la posibilidad de que los laicos ejerzan todos los 
oficios y responsabilidades eclesiales excepto aquellos que sean intrínsecamente jerárquicos, por estar directamente vinculados con la autoridad y capitalidad propia del ministerio de los Pastores.

Por último, respecto al ejercicio de la ministerialidad laical en el ámbito del munus santificandi de la Iglesia, convendría revisar la regulación positiva de algunas limitaciones legales para una mayor y más activa participación del laicado en esta dimensión, como las relativas a la posibilidad de asistir a matrimonios. Y, sobre todo, como puso ya de manifiesto el Sínodo de la Palabra de 2008, ha llegado la hora de replantearse, desde el reconocimiento de la específica ministerialidad laical y de la radical igualdad de todos los bautizados y, más aún, de todos los laicos, la conveniencia de suprimir la injusta preterición de la mujer en la admisión a los ministerios estables del lectorado y acolitado.

En definitiva, el Derecho Canónico abre significativas vías de corresponsabilidad y participación laical en la vida y misión de la Iglesia, que deberán ser implementadas sin miedos ni reticencias, desde la convicción de que la sinodalidad es un don y una dimensión fundamental de la Iglesia. Asimismo, acogiendo la llamada del Papa a la conversión pastoral y a una renovación y sinodal de las estructuras eclesiales, será necesario también hacer un ejercicio de discernimiento sobre aquellos aspectos a mejorar en la actual regulación y praxis, favoreciendo una mejor vivencia de esta dimensión, que integre adecuadamente las aportaciones del entero Pueblo de Dios, incluidos los laicos, en la vida y misión de la Iglesia. 


\section{Bibliografía}

AA. VV., La misión del laico en la Iglesia y en el mundo, Eunsa, Pamplona 1987.

Arroba Conde, M. J., Giusto processo e peculiarità culturali del processo canonico, Aracne, Roma 2016.

—, La pastoral judicial y la preparación de la causa en el motu proprio Mitis Iudex Dominus Iesus, en M. E. Olmos Ortega (ed.), Procesos de nulidad matrimonial tras la reforma del papa Francisco, Dykinson, Madrid 2016, 63-82.

Arroba Conde, M. J. - IzZI, C., Pastorale giudiziaria e prassi processuale nelle cause di nullità del matrimonio. Dopo la riforma operata con il Motu proprio Mitis Iudex Dominus Iesus, San Paolo, Cinisello Balsamo 2017.

Bahillo, T., Presencia de religiosos laicos en institutos clericales. Institutos mixtos, ¿posibilidad real o vía sin salida?, Estudios Eclesiásticos 89 (2014) 675-699.

Baldisseri, L. (ed.), A cinquant'anni dall'Apostolica Sollicitudo. Il Sinodo dei Vescovi al servizio di una Chiesa sinodale. Atti del Seminario di studio organizzato dalla Segreteria generale del Sinodo dei Vescovi (Città del Vaticano, 6-9 febbraio 2016), Libreria Editrice Vaticana, Città del Vaticano 2016.

BEaL, J. P., The Exercise of the Power of Governance by Lay People: State of the Question, The Jurist 55 (1995) 1-92.

BEYER, J., Iudex laicus vir vel mulier, Periodica de re canonica 75 (1986) 29-60.

BLANCO, M., La mujer en el ordenamiento jurídico canónico, Revista General de Derecho Canónico y Derecho Eclesiástico del Estado 20 (2009) 15 (www.iustel.com).

BonI, G., La recente riforma del processo di nullità matrimoniale. Problemi, criticità, dubbi (parte terza), Stato, Chiese e pluralismo confessionale 11 (2016) 1-82.

Cenalmor, D., Sub c. 214, en Comentario exegético al Código de Derecho Canónico, II, Eunsa, Pamplona 1996, 99-108.

Ciudad Albertos, A., Actuales expresiones canónicas de sinodalidad, Scripta Theologica 48 (2016) 707-730. 
COMisión TeOlÓgICA INTERNACIONAL, La sinodalidad en la vida y misión de la Iglesia, 2018: http://www.vatican.va/roman_curia/congregations/cfaith/cti_documents/rc_cti_20180302_sinodalita_sp.html (consultado el 16 de abril de 2019).

Daniel, W. L., An Analysis of Pope Francis' 2015 Reform of the General Legislation governing Causes of Nullity of Marriage, The Jurist 75 (2015) 429-466.

Díaz Moreno, J. M., Los fieles cristianos y los laicos, en M. Cortés J. San José (coords.), Derecho Canónico, vol. I: El Derecho del Pueblo de Dios, BAC, Madrid 2006, 155-185.

ERDÖ, P., Questiones de officiis ecclesiasticis laicorum, Periodica de re canonica 81 (1992) 167-186.

FÉlix Ballesta, M. A., La mujer en el Derecho Canónico, en C. Melero (ed.), XV Fornadas de la Asociación Española de Canonistas en el XXV Aniversario de su fundación, UPSA, Salamanca 1997, 99-135.

Fuentes, J. A. (ed.), Las asociaciones de fieles. Aspectos canónicos y civiles, Eunsa, Pamplona 2011.

HEREDIA EsTEBAN, F., La parroquia "in solidum": una respuesta a nuevas necesidades, Revista Española de Derecho Canónico 66 (2009) 551-585.

IzZI, C., I ministri di giustizia in genere (artt. 33-37), en P. A. BONNET C. Gullo (a cura di), Il giudizio di nullità matrimoniale dopo l'Istruzione "Dignitas Connubii". Parte seconda: la parte statica del processo, Libreria Editrice Vaticana, Città del Vaticano 2007, 103-130.

Llobell, J., I processi matrimoniali nella Chiesa, EDUSC, Roma 2015.

MANZANAREs, J., La figura del laico en el Sínodo episcopal de 1987, en AA. VV., El laicado en la Iglesia, UPSA, Salamanca 1989, 77-95.

MCDonough, E., Furisdiction exercised by non-ordained member in Religious Institutes, CLSA Proceedings 58 (1996) 292-307.

Musselli, L., Il giudice laico come "estensore" nei tribunali ecclesiastici, en M. Vismara Missiroli - M. Madonna - A. Tira - C. E. Veralda (a cura di), Società civile e società religiosa tra diritto e storia. Scritti scelti, Wolters Kluver-Cedam, Padova 2016, 89-106.

Navarro, L., La condizione giuridica del laico nella canonistica dal Concilio Vaticano II ad oggi, Ius Ecclesiae 23 (2011) 319-338. 
Olmos Ortega, M. E., Los laicos en los órganos de gobierno de la Iglesia (con especial referencia a la mujer), en AA. VV., El laicado en la Iglesia, UPSA, Salamanca 1989, 97-122.

PEÑA, C., Il M.P. Mitis Iudex alla luce delle difficoltà sollevate dal Questionario presinodale e delle richieste emerse nei Sinodi sulla famiglia. Indagine Pregiudiziale o Pastorale, en Le Regole procedurali della Mitis Iudex Dominus Iesus. Linee guida per un'azione pastorale nel solco della giustizia, Libreria Editrice Vaticana, Città del Vaticano 2019, 11-28.

—, Diaconado femenino y ministerios: aportaciones canónicas para la reflexión teológica, en S. MARTínez CANO - C. Soto (eds.), Mujeres y diaconado. Sobre los ministerios en la Iglesia, Verbo Divino (Aletheia), en prensa.

- Presencia de la mujer en la Iglesia desde la perspectiva jurídico-canónica, Confer 56 (2017) 401-414.

- Nueva regulación de las nulidades matrimoniales. Claves de lectura de una relevante reforma procesal, Sal Terrae 104 (2016) 257-269.

- ¿ ¿iaconisas? Apuntes canónicos para la reflexión, Vida Nueva, no 2.989 , 21-27 de mayo de 2016, 26-28.

- La reforma de los procesos canónicos de nulidad matrimonial: el motu proprio 'Mitis Iudex Dominus Iesus', Estudios Eclesiásticos 90 (2015) 621682.

- La aplicación de la Instrucción Dignitas Connubii en España: valoración y sugerencias de mejora tras 10 años de vigencia, Periodica de re canonica 104 (2015) 517-543.

-, La vocación laical: marco canónico, en E. EsTÉvEZ (coord.), Hombres y mujeres de Espíritu en el siglo XXI, UPSA (Cátedra Pedro Poveda 8), Salamanca 2012, 409-419.

-, Status jurídico de la mujer en el ordenamiento de la Iglesia, Revista Española de Derecho Canónico 54 (1997) 685-700.

Pontificio Consejo Para la InTERPRetación de TeXTos LegISLATIVOS, Acta et documenta PCCICIR. Congregatio plenaria diebus 20-29 octobris 1981 babita, LEV, Ciudad del Vaticano 1991.

Provost, J. H., Role of Lay Fudges, The Jurist 45 (1985) 301-333.

REA, F. S., L'esercizio della potestà giudiziaria del fedele laico attraverso il prisma della Potestas gubernandi in Ecclesia. Sollecitazioni teologiche e ca- 
nonistiche per una "Chiesa in uscita", Stato, Chiese e pluralismo confessionale (www.statoechiese.it) 37 (2018) 1-61.

TAVANI, A. P., I laici e la funzione giudiziaria, en AA. VV., I soggetti nel nuovo processo matrimoniale canonico. Atti del XLVIII Congresso Nazionale di Diritto Canonico. Udine, 5-8 settembre 2016, Libreria Editrice Vaticana, Città del Vaticano 2018, 185-202.

VIANA, A., Sinodalidad y Derecho canónico. Un seminario organizado por la Secretaría general del Sínodo de los Obispos, Estudios Eclesiásticos 92 (2017) 683-701.

-, Consultar no es informar de una decisión ya tomada. Comentario de la sentencia de la Signatura Apostólica de 27 de noviembre de 2012, Ius Canonicum 55 (2015) 763-767.

—, El problema de la participación de los laicos en la potestad de régimen: dos vías de solución, Ius Canonicum 54 (2014) 603-638.

-, Atención de parroquias en situaciones de escasez de clero. El supuesto del canon 5172 del CIC, Telmus: Anuario del Instituto Teológico San José (2010) 83-105.

VITALI, D., I soggetti della sinodalità alla luce dell'ecclesiologia del Concilio Vaticano II, en L. BALDISSERI (ed.), A cinquant'anni dall'Apostolica Sollicitudo. Il Sinodo dei Vescovi al servizio di una Chiesa sinodale. Atti del Seminario di studio organizzato dalla Segreteria generale del Sinodo dei Vescovi (Città del Vaticano, 6-9 febbraio 2016), Libreria Editrice Vaticana, Città del Vaticano 2016, 141-189. 
